\title{
Structural insights and the surprisingly low mechanical stability of the Au-S bond in the gold-specific protein GolB
}

\author{
Wei Wei ${ }^{\dagger, \ddagger, \#}$, Yang Sun ${ }^{\S, \#, ~ M i n g l i ~ Z h u \dagger, ~ \ddagger, ~ X i a n g z h i ~ L i u ~}{ }^{\dagger, \ddagger}$, Peiqing Sun ${ }^{\dagger} \neq$, Feng Wang", Qiu \\ Gui $^{\ddagger}$, Wuyi Meng", Yi Cao ${ }^{\S}$, Jing Zhao ${ }^{\dagger \neq *}$ \\ † State Key Laboratory of Coordination Chemistry, Institute of Chemistry and BioMedical Sciences, School of \\ Chemistry and Chemical Engineering, Collaborative Innovation Center of Chemistry for Life Sciences, Nanjing \\ University, Nanjing 210093, China; \\ ‡ State Key Laboratory of Pharmaceutical Biotechnology, School of Life Sciences, Nanjing University, Nanjing \\ 210093, China; \\ $\S$ Collaborative Innovation Center of Advanced Microstructures, National Laboratory of Solid State \\ Microstructure, Department of Physics, Nanjing University, Nanjing 210093, China; \\ "Elias James Corey Institute of Biomedical Research, Wuxi Biortus Biosciences Co., Ltd, Jiangyin, 214437, China; \\ \# These authors contributed equally to this work.
}

\section{Experimental Section.}

Protein expression. The plasmid of Salmonella typhimurium golb gene is a generous gift from Prof. Chuan He at The University of Chicago. The gene encoding the protein GolB protein (GMQFHIDDMTCGGCASTVKKTILTLDANATVRTDPATRLVDVETSLSAEQIAAALQKAGFPPRER) was amplified from the plasmid by standard polymerase chain reaction (PCR) methods. The fusion protein $6 \times$ His-MBP-TEV-GolB was sub-cloned into a pET28a vector, and the resulting construct was subsequently transformed into BL21 (DE3) cells. The fusion protein was expressed in LB medium containing $50 \mu \mathrm{g} / \mathrm{mL}$ kanamycin after induction with $1 \mathrm{mM}$ IPTG at $15^{\circ} \mathrm{C}$. To obtain purified GolB, E.coli BL21 (DE3) cells containing the recombinant plasmid that had been cultured overnight were collected by centrifugation. The pellet was re-suspended in buffer $(50 \mathrm{mM}$ Tris- $\mathrm{HCl} \mathrm{pH} 7.0,500 \mathrm{mM} \mathrm{NaCl}$ and $5 \%$ v/v glycerol) and dissociated by microfluid. The supernatant was obtained by centrifuging the cell lysate at $20,000 \mathrm{rpm}$ and $277 \mathrm{~K}$ for $1 \mathrm{~h}$. Standard Ni-affinity chromatography (His-Trap FF) was performed for preliminary purification of the His-tagged fusion protein from the supernatant. The enrichment fusion protein was digested by TEV protease at $277 \mathrm{~K}$ overnight. Ni-affinity chromatography (His Trap HP) was used again to obtain GolB, which was separated from the $6 \times$ His-MBP-TEV fusion protein. High purity GolB was obtained after further purified by size-exclusion chromatography (Superdex 30) and was concentrated.

Crystallization. Crystal screening was performed at $293 \mathrm{~K}$ by the sitting-drop vapour-diffusion method. A 200 nanolitre protein solution $(4.43 \mathrm{mM})$ was mixed with 200 nanolitre reservoir solution and equilibrated against 30 microlitre reservoir solution. Commercial crystallization kits from Hampton Research and Qiagen were used for crystal screening. Initial crystals of GolB were observed under the following condition: 2.0 M ammonium citrate tribasic pH 7.0, o.1 M BIS-TRIS propane pH 7.o. Single crystals were obtained by further optimization of salt concentration and $\mathrm{pH}$ values. For heavy atom derivative crystals preparation, we added $10 \mathrm{mM} \mathrm{KAu}(\mathrm{CN})_{2}$ to a cryo-protection solution (2.0 M ammonium citrate tribasic $\mathrm{pH}$ 7.0, o.1 
M BIS-TRIS propane $\mathrm{pH}$ 7.0, 25\% glycerol), soaked the crystals for about 4 hoursand then the data were collected at home source diffraction system.

Single-molecule AFM. First, the gene encoding the protein GolB with a $\beta$-hairpin fragment (15 aa EWTYDDATKTFIVTE)

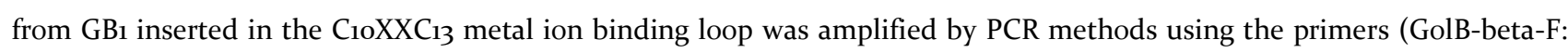
CGGGATCCATGCAGTTCCATATTGATGACATGACCTGCGGCGAATGGACCTACGACGACGCTACCAAAACCTTCACGGTTA CCGAAGGCTGCGCCAGTACGGTAAAAAAGA and GolB-R: GGGGTACCTTACTAAGATCTCCTCTCGCGCGGCGGGAAAC). Then the gene encoding the (beta GB1-GolB) 4 hybrid polyprotein was constructed using standard molecular biology techniques to splice GB1 and GolB with $\beta$-hairpin in an iterative approach". (beta GB1-GolB) 4 was expressed in BL21 and purified by $\mathrm{Ni}^{2+}$-affinity chromatography. Single-molecule AFM experiments were performed on a commercial AFM (NanoWizard II, JPK Instruments, Berlin, Germany). In the force spectroscopy experiments, we first deposited $30 \mu \mathrm{L}$ of the protein at a concentration of around $0.3 \mathrm{mg} / \mathrm{mL}$ on a glass substrate for $5 \mathrm{~min}$. Next, we filled in the fluid chamber with 1.5 $\mathrm{mL}$ Tris- $\mathrm{HCl}$ buffer ( $\mathrm{pH}$ 7.4). Based on equipartition theorem, the cantilever (MLCT, BRUKER, USA) with a spring constant of $\sim 40 \mathrm{pN} / \mathrm{nm}$ was then calibrated after equilibrating in the solution for around $30 \mathrm{~min}$. In a typical experiment, the cantilever was brought into contact with the surface at a constant speed of $1000 \mathrm{~nm} / \mathrm{s}$. Then the cantilever stayed on the surface with a contact force of around $9 \mathrm{nN}$ for $1.5 \mathrm{~s}$ to to ensure the adhesion between protein and the tip. Subsequently, the cantilever was retracted to stretch the protein molecule being picked up from the surface. The force curves were recorded automatically by the software from JPK and then analyzed by a home-written protocol in Igor 6.37 (WaveMetrics, Lake Oswego, OR). At least 200 events were recorded of each protein and the force distributions were then fitted by Gaussian distribution.

UV-visible measurement of metal binding experiment. The (beta GB1-GolB) 4 and (GB1-GolB) 4 polyprotein were reduced with $1 \mathrm{mM}$ DTT overnight at $4{ }^{\circ} \mathrm{C}$ and passed through 10 DG desalting column using $100 \mathrm{mM} \mathrm{NaCl}, 100 \mathrm{mM}$ Tris- $\mathrm{HCl}, \mathrm{pH}$ 7.5. About $1 \mu \mathrm{M}$ of GolB protein was used immediately for gold (I) binding experiment in the same buffer. For all measurements, baseline was recorded with protein itself and UV spectra differences were recorded for each measurement. Gold(I) binding was monitored as an increase in absorption band at $250-255 \mathrm{~nm}^{2,3}$. Concentration and absorbance were corrected for final volume.

Circular dichroism experiments. (Beta $\mathrm{GB1}-\mathrm{GolB})_{4}$ and (GB1-GolB) ${ }_{4}$ s (around $0.04 \mathrm{mg} / \mathrm{mL}$ ) $\mathrm{CD}$ spectra in $1 \times \mathrm{PB}$ was obtained by JASCO J-815 CD spectropolarimeter (JASCO, Japan). The experiment was done in a quartz cell with o.1mm path length from $250 \mathrm{onm}$ to $190 \mathrm{onm}$ wavelength at the room temperature. 
A

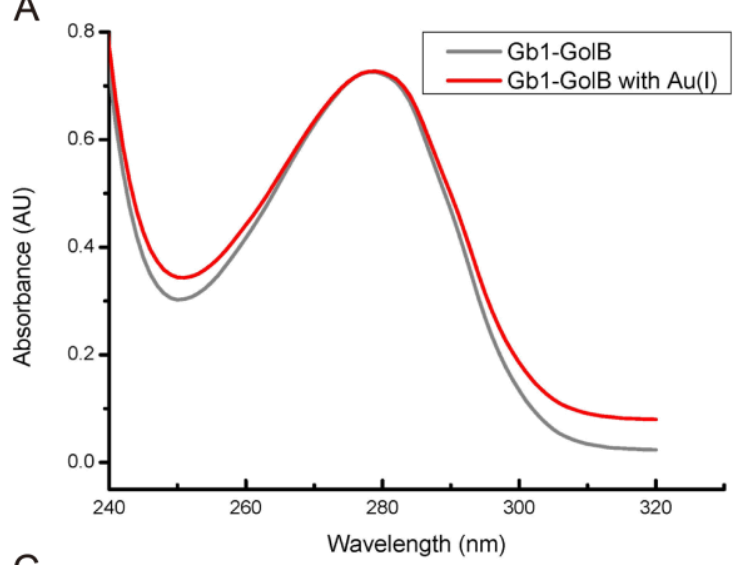

C

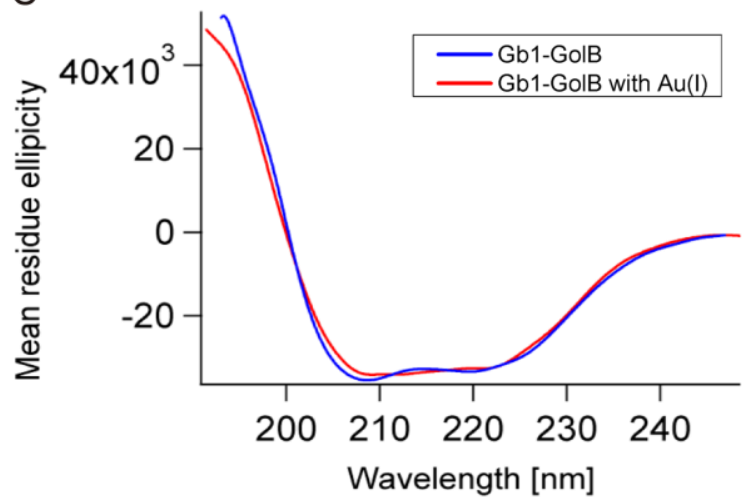

B

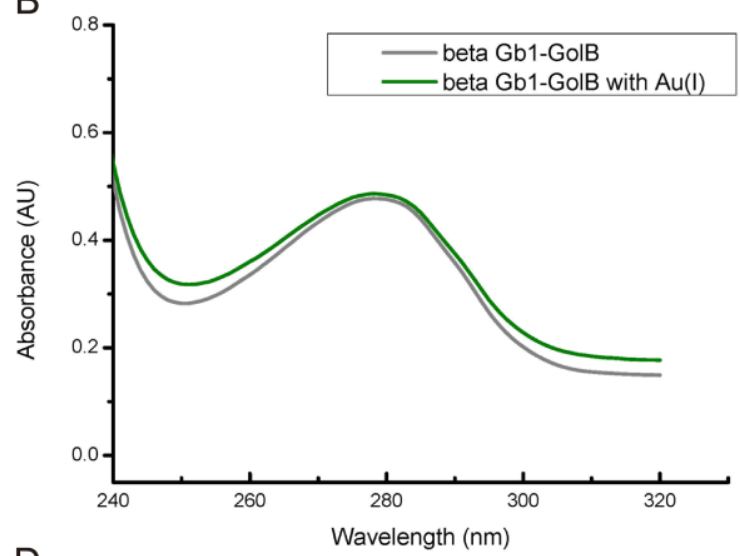

D

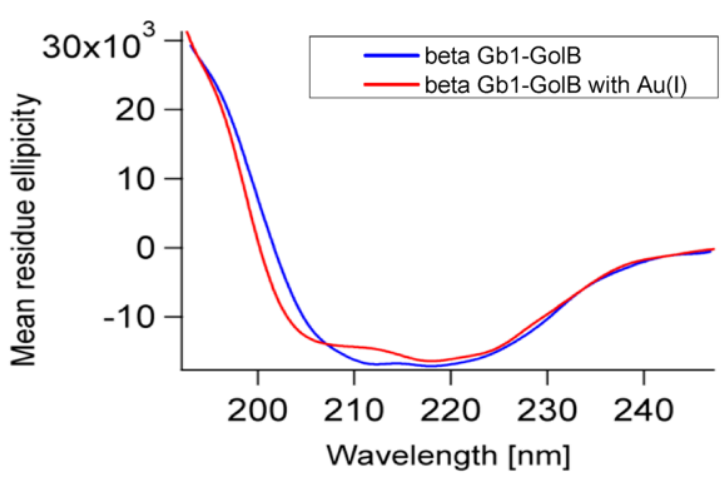

Figure S1 UV-vis spectra of (GBi-GolB) 4 protein loaded with $\mathrm{Au}(\mathrm{I})$ (A), (beta GB1-GolB) 4 protein loaded with $\mathrm{Au}(\mathrm{I})(\mathrm{B}), \mathrm{CD}$ spectra of $(\mathrm{GB1}-\mathrm{GolB})_{4}$ protein loaded with $\mathrm{Au}(\mathrm{I})(\mathrm{C})$ and (beta GBi-GolB) 4 protein loaded with $\mathrm{Au}(\mathrm{I})(\mathrm{D})$. 


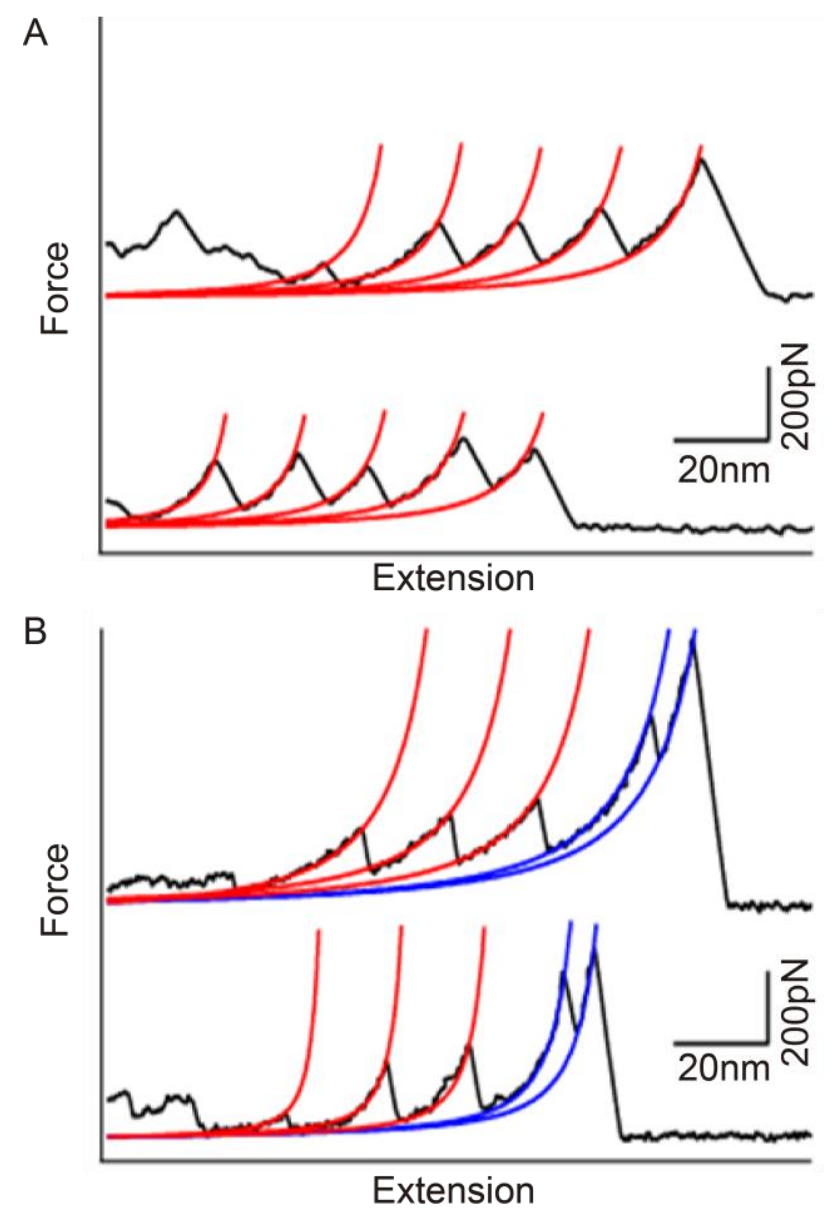

Figure S2 Representative curves for stretching (GB1-GolB) 4 (A) and (beta GB1-GolB) 4 under oxidation conditions (B). Cys ${ }^{10}$ and $\mathrm{Cys}^{13}$ of GolB form intramolecular disulphide bonds in the polyprotein. Clearly, no unfolding events of GolB can be detected in both proteins, indicating that GolB is mechanically labile and unfolds at forces below the force detection limit of our AFM setup $(\sim 10 \mathrm{pN})$. Because the loop trapped by $\mathrm{Cys}^{10}$ and $\mathrm{Cys}^{13}$ in wild type GolB is too short, we can only resolve the rupture events of disulphide bonds in GolB with loop insertion $(\sim 9 \mathrm{~nm})$ in some cases (highlighted in blue). However, because the rupture forces for disulfide bonds are much higher than the nonspecific interaction forces used to attach the polyprotein to the cantilever and the substrate, the number of events corresponding to rupture disulfide bonds are much less than the number of events for GB1 unfolding. Clearly, the rupture forces for disulfide bonds are much higher than the rupture forces for $\mathrm{Au}(\mathrm{I})-\mathrm{S}$ or $\mathrm{Cu}(\mathrm{I})-\mathrm{S}$ bonds in holo GolB. 
Table Sı Crystallization Method

\begin{tabular}{ll}
\hline Method & Sitting-drop vapour-diffusion \\
Plate type & Corning 3552 \\
Temperature (K) & 293 \\
Protein concentration & $31 \mathrm{mg} / \mathrm{mL}$ \\
Buffer composition of protein solution & $50 \mathrm{mM} \mathrm{Tris-HCl} \mathrm{pH} \mathrm{7.5,} \mathrm{200} \mathrm{mM} \mathrm{NaCl.}$ \\
Composition of reservoir solution & $2.0 \mathrm{M} \mathrm{Ammonium} \mathrm{citrate} \mathrm{tribasic} \mathrm{pH} \mathrm{7.0,} \mathrm{o.1} \mathrm{M} \mathrm{BIS-TRIS} \mathrm{propane}$ \\
Volume and ratio of drop & $\mathrm{pH} 7.0$. \\
Volume of reservoir & $200 \mathrm{~nL}$ protein/200 nL reservoir \\
\hline
\end{tabular}


Table S2 Data collection and processing

We finished all of the data collection works by use F-RE++ and R-AXIS IV of RIGAKU.

\begin{tabular}{|c|c|c|c|c|}
\hline & Native & GolB $(\mathrm{Au}+$ soak $)$ & GolB(TCEP soak) & $\begin{array}{l}\text { GolB(TCEP and } \\
\text { Au+ soak) }\end{array}$ \\
\hline Diffraction source & RIGAKU F-RE++ & RIGAKU F-RE++ & RIGAKU F-RE++ & RIGAKU F-RE++ \\
\hline Wavelength $(\AA)$ & 1.54 & 1.54 & 1.54 & 1.54 \\
\hline Temperature (K) & 100 & 100 & 100 & 100 \\
\hline Detector & R-AXIS IV & R-AXIS IV & R-AXIS IV & R-AXIS IV \\
\hline $\begin{array}{l}\text { Crystal-detector } \\
\text { distance }(\mathrm{mm})\end{array}$ & 90 & 90 & 130 & 140 \\
\hline $\begin{array}{l}\text { Rotation range } \\
\text { per image }\left(^{\circ}\right)\end{array}$ & 0.5 & 0.5 & 0.5 & 0.5 \\
\hline $\begin{array}{l}\text { Total rotation } \\
\text { range }\left(^{\circ}\right)\end{array}$ & 180 & 180 & 90 & 120 \\
\hline $\begin{array}{l}\text { Exposure time per } \\
\text { image (s) }\end{array}$ & 360 & 300 & 300 & 300 \\
\hline Space group & P65 22 & P65 22 & P65 22 & P65 22 \\
\hline a, b, c $(\AA)$ & $36.993,36.993,169.761$ & $37.462,37.462,167.976$ & $\begin{array}{l}37.007, \\
169.932\end{array}$ & $\begin{array}{l}37.093, \quad 37.093 \\
169.911\end{array}$ \\
\hline$\alpha, \beta, \gamma\left({ }^{\circ}\right)$ & $90,90,120$ & $90,90,120$ & $90,90,120$ & $90,90,120$ \\
\hline \multicolumn{5}{|l|}{ Mosaicity $\left(^{\circ}\right)$} \\
\hline $\begin{array}{l}\text { Resolution range } \\
(\AA ̊)\end{array}$ & $50.00-1.40$ & $50.00-1.41$ & $50.00-1.80$ & $50.00-2.00$ \\
\hline $\begin{array}{l}\text { Total No. of } \\
\text { reflections }\end{array}$ & 221204 & 199923 & 51000 & 66890 \\
\hline $\begin{array}{l}\text { No. of unique } \\
\text { reflections }\end{array}$ & 22949 & 23974 & 7012 & 5297 \\
\hline Completeness (\%) & $99.1(93.1)$ & $93.9(42.3)$ & 97.8 (96.9) & $99 \cdot 5(100)$ \\
\hline Redundancy & $9.64(3.04)$ & $8.43(1.56)$ & $7 \cdot 3(5.0)$ & $12.6(9.1)$ \\
\hline$\langle\mathrm{I} / \sigma(\mathrm{I})\rangle$ & $20.25(1.78)$ & $19.05(2.26)$ & $34.28(1.38)$ & $52.94(20.35)$ \\
\hline Rr.i.m. & $5.0 \%(62.7 \%)$ & $6.9 \%(48.8 \%)$ & $4.5 \%(9.6 \%)$ & $7.0 \%(12.0 \%)$ \\
\hline $\begin{array}{l}\text { Overall B factor } \\
\text { from Wilson plot } \\
(\AA ̊ 2)\end{array}$ & & & 18.061 & 17.090 \\
\hline
\end{tabular}

† Only the redundancy-independent merging $\mathrm{R}$ factor $\mathrm{R}_{\mathrm{r} \text {.i.m. }}$ or $\mathrm{R}_{\text {meas }}$ should be reported. If these values are not available, they may be estimated by multiplying the conventional $R_{\text {merge }}$ value by the factor $[N /(N-1)] 1 / 2$, where $N$ is the data multiplicity [the $R_{\text {r.i.m }}$ are estimated from $R_{\text {merge }}$ value as suggested.].

$\ddagger$ State here if there are any anomalies in the Wilson plot, such as spikes arising from ice rings, etc. 
Table S3 Statistics of Refinement

\begin{tabular}{|c|c|c|}
\hline & Native & GolB (TCEP and Au+ soak) \\
\hline R factor $\ddagger(\%)$ & 16.6 & 20.8 \\
\hline Rfreeł $(\%)$ & 19.1 & 23.9 \\
\hline \multicolumn{3}{|c|}{ R.m.s. deviation from ideal geometry } \\
\hline Bonds $(\AA)$ & 0.007 & 0.01 \\
\hline Angles $\left(^{\circ}\right)$ & 1.256 & 0.90 \\
\hline Rms ChirVolume & 0.064 & 0.031 \\
\hline \multicolumn{3}{|l|}{ Non-crystallography contents } \\
\hline Molecules & 1 & 1 \\
\hline Redisues & 65 & 62 \\
\hline Waters & 61 & 35 \\
\hline $\mathrm{Au}$ & - & 2 \\
\hline \multicolumn{3}{|l|}{ Ramachandran } \\
\hline Preferred regions & $96.88 \%$ & $97 \cdot 77 \%$ \\
\hline Allowed regions & $3.12 \%$ & $3.23 \%$ \\
\hline outliers & o & o \\
\hline
\end{tabular}

\section{REFERENCES}

(1) Lv, C.; Gao, X.; Li, W.; Xue, B.; Qin, M.; Burtnick, L. D.; Zhou, H.; Cao, Y.; Robinson, R. C.; Wang, W. Nat. Commun. 2014, 5 .

(2) Jian, X.; Wasinger, E. C.; Lockard, J. V.; Chen, L. X.; He, C. J. Am. Chem. Soc. 2009, 131, 10869.

(3) Wei, W.; Zhu, T.; Wang, Y.; Yang, H.; Hao, Z.; Chen, P. R.; Zhao, J. Chem. Sci. 2012, 3, 1780. 